\section{Aetiology of Multiple Sclerosis}

SIR,-In your leading article on the aetiology of multiple sclerosis (20 February, p. 466) you stress the lack of convincing evidence concerning the pathogenesis of this disease.

In this context it is not remiss to draw attention to the paper by Barlow in which he re-states the well-known facts about the geographical distribution of multiple sclerosis. This is all the more impressive to those who have lived in areas where the disease, for all practical purposes, does not exist in nativeborn subjects of all races. Under these circumstances, it is difficult to accept a dietary, autoimmune, or viral pathogenesis as being of primary significance. On the other hand, as Barlow points out, there is a correlation between the distribution of the disease, certain geomagnetic latitudes (40 and 50 degrees), and the density of cosmic radiation. Moreover, it - is tempting to see a relationship between the scatter of C.N.S. lesions, the scatter of the disease in the population at risk, and the scatter of cosmic radiation. On present evidence this possible relationship seems no more improbable than some of the current hypotheses; and is certainly worth further investigation.-I am, etc.

Regina,
Saskatchewan, Canada. H. JACOBS.

REFERENCE ' Barlow, J. S., Acta psychiat. scand., 1960, 35,
Suppl. 147, 108.

\section{Behaviour Therapy}

SIR,-Members of Professor Eysenck's department may have been surprised to see themselves described as " novices in behaviour therapy" by Professor Wolpe in his letter (19 June, p. 1609). We did not treat the cases reported in our paper; most were treated by psychologists, a few by psychiatrists in training. Several of the psychologists had made important contributions to the development of behaviour therapy, and, to answer Dr. Watt's point (29 May, p. 1434), all were enthusiastic.

Our experience does not confirm Professor Wolpe's statement that "conventional clinical experience actually [was] ... a handicap in behaviour therapy." Psychiatrists obtained good results with suitable patients both in this and another series. ${ }^{1}$ As with most treatments, results depend on the type of syndrome as well as on the skill of the therapist (and of course many other factors). As we demonstrated in our paper, overall improvement rates from mixed groups of neurotic patients, in the absence of controls, can tell us little about the value and indications of a new treatment. We would welcome the results of a careful controlled trial and follow up by Professor Wolpe. Until this is available, our results seem more likely to represent those which others can expect in a busy psychiatric clinic.

Professor Wolpe states that we pared down by $14 \%$ the improvement rate of $89 \%$ obtained in his uncontrolled series without complete follow-up, by " adding to the total of cases a number who had consulted him but who had not undergone behaviour therapy." This might mislead readers who are unaware that in $1961^{23}$ he stated that the disputed
$14 \%$ contains patients who left before 15 sessions of treatment. We are not the only ones to point out inconsistencies in some of Professor Wolpe's data, ${ }^{5}$ and to stress the importance of knowing the outcome of all patients who start treatment.

Dr. Watt also suggests that we could have controlled the usual hospital influences, drugs, and supportive interviews which were often given to patients receiving behaviour therapy. We could not, of course, do this in a retrospective study, but the control group was included to assess the efforts of just these factors. Both groups were subject to the influences Dr. Watt mentions, but the behaviour therapy group had deconditioning treatment as well.

Dr. Watt also questions what we mean by pointing out the importance of clinical skill in treating neurotic patients. We did not mean, as he suggests, that all neurotic patients receive a form of behaviour therapy (although there are many factors in common between behaviour therapy and other forms of psychological healing), but meant that the successful application of re-learning therapies requires not only a knowledge of learning theory but also clinical skills in treating patients, just as the successful use of new drugs requires more than a detailed knowledge of pharmacology.

We agree with Dr. Snaith's comment (29 May, p. 1434) that only certain neurotic syndromes can easily be accepted as learnt behaviour patterns. Unfortunately, however, not everyone agrees what "can fairly be thought to be learnt." Professor Wolpe, for example, considers all neuroses to be learnt maladaptive patterns of behaviour, and includes agoraphobia, which Dr. Snaith would exclude from the field of behaviour therapy. This issue is more fully discussed in another paper. 'Space did not allow us, unfortunately, to give full details of the techniques employed in each case, but, in reply to Dr. Snaith's point, underlying anxiety-elevating factors were sought in the obsessive-compulsive patients and dealt with when found.

Finally, it would be a pity if Professor Wolpe's intemperate claims were to turn others away from the technique of behaviour therapy which he developed; a technique which, applied to appropriately selected patients, is of great value, but which is not a panacea for neurosis.-We are, etc.,

\section{J. E. COOper.}

M. G. Gelder.

Institute of Psychiatry, The Maudsley Hospital,

I. M. MARKS.

\section{REFERENCES}

Gelder, M. G., Marks, I. M., Sakinofsky, I., and Wolf, H. H., 6th International Congress of Psychotherapy, 1964. London.

2 Wolpe, J., 1961, personal communication.

Cooper, J.' E., Lancet, $1963,1,411$. Marks, I. M., and Gelder, M. G., Brit. f. Msychiat., 1965, in press. Psychiat., 1965, in press.
Forrest, A., Brit. F. med. Psychol., 1965, 38, 181.

\section{New Drugs of Addiction}

SIR,-In treating addicts it becomes apparent from time to time that old tablets are being used in new ways, and perhaps new drugs of addiction are becoming of increasing importance.

I would like to draw doctors' attention to the current use of ephedrine tablets. These are being used in increasing quantities by young people for "kicks," and they are also occasionally being used for intravenous injections ("main lining"). This in spite of the fact that they are not very soluble in water, and occasionally block the syringes. I therefore think that care and caution should be called for in prescribing these tablets at the present time.

There is also an increasing amount of pethidine addicts coming to notice, who are obtaining their supplies from some black market. To my personal knowledge through patients, this black market has existed for some years, but I believe it is growing at the present time.

Finally, mescaline (Peyote) in the form of a cactus plant seems to be either grown in this country or imported illicitly, and the users of this are describing its euphoriant effect in the sort of terms such as, "it is a thousand times better than cannabis."

I therefore feel that increasing vigilance in the use of " psychotomimetic" drugs is necessary.-I am, etc.,

P. A. L. Chapple,
Secretary, London Committee for
Study of Drug Addiction.
West Park Hospital,
Epsom, Surrey.

\section{Identification of Tablets}

SIR,-The Identification of Tablets Subcommittee of the Joint Committee of the B.M.A. and the Pharmaceutical Society is reported (Supplement, 8 May, p. 179) to have decided not to recommend identification of tablets by code; and it appears from the context that, in particular, the Subcommittee was opposed to "Co-tab" coded tablets.

This is difficult to understand when one recalls that in 1959 and 1960 the Annual Representative Meeting called for some means of tablet identification ${ }^{1}$; and that in 1963 the Representatives of Local Medical Committees called specifically for tablet coding. ${ }^{2}$ The sponsor of the relevant motion then said that "it was for the manufacturers, not the profession, to devise a suitable system." In addition, in 1962 a Subcommittee of the Central Health Services Council's Standing Medical Advisory Committee ${ }^{3}$ specifically asked that a system of letters and numbers should be adoped which .... would provide an infallible means of establishing the origin and composition of every tablet in the pharmaceutical range." Why, when a particular manufacturer-doubtless for good commercial reasons-makes a first major step in the direction demanded over the years by the profession, should its action be coldshouldered ? - I am, etc.,

Brighton 7

\section{S. HACKING}

\section{REFERENCES}

Brit. med. F., 1961, 1, Suppl. 171 Ibid., 1963, 2, Suppl. 21. Central Health Services Council Standing Medical
Advisory Committee. Report of the Sub-
committee: Emergency Treatment in Hospital
of Cases of Acute Poisoning, 1962. London.
H.M.S.O.

SIR,-In a recent report of the B.P. Commission $^{1}$ to the Pharmacopoeia Committee of the General Medical Council, the Commission states that there are "urgent and compelling reasons why immediate steps should be taken to facilitate methods of identification of dispensed medicines." The Commission favours the labelling of containers of dispensed medi- 
cines and is against the identification of tablets by a system of markings on the grounds that to make this work, firstly it needs to be mandatory (a view with which I entirely agree), and secondly that it would take a "considerable time to elaborate and to put into use." I am not in agreement with this second reasoning, with the existence of CoTabs for standard tablets already, and the latest recommendation of the Association of British Pharmaceutical Industry to their member companies to the effect that each company should include on their tablets a house mark specific to that company's products and an additional identifying mark to identify each separate ethical product out of that company's range.

It would seem that with a little good will between the B.M.A., Pharmaceutical Society, and A.B.P.I. (who have discussed the problem of tablet identification jointly on two occasions within the last year) on the one hand and the Commission on the other, a scheme of tablet identification could well be elaborated and put into use nationally, if not internationally. The Government are particularly interested in the legislation of medicines at present, and now would seem to be the appropriate time for the four bodies to put forward such a scheme.

Are there not "urgent and compelling reasons" to achieve tablet identification as well as the labelling of containers when it is well known that of all medications tablets are especially prone to be swapped from one container to another by patients ? Surely, tablets being the most commonly prescribed form of medication, there should be some provision to ensure that the marking on a tablet confirm the label on the container, thus avoiding the situation of a possibly incorrect tablet identification.

I am entirely in favour of labelling the container, because not only will it cover tablets but it will also cover liquid medicines and ointments; but I feel that we should strive for both measures so that tablets are in fact fully safeguarded as regards identification.I am, etc.,

\section{Sutton Coldfield \\ J. D. W. WhitNey.}

REFERENCE

1 Chemist and Druggist, 29 May 1965, p. 547.

\section{Africa's Needs}

SIR,-In the past several issues of the B.M.F. I have read many opinions of what Africa needs in the way of medical help. Some of these opinions are practical, but all too many are woolly-minded generalizations of high-minded principles that one expects to hear from a pulpit and not from medical men. ing :

Bluntly, what Africa needs is the follow-

(1) Fewer experts coming out here on quick surveys, wasting various organizations' money and our limited time in talking, showing them around, pleading with them for a more practical approach, etc. I estimate the air fares saved in one year would pay at least one firstclass specialist's salary for the same period.

(2) Doctors of any specialty or in general practice, who will come out here and stay long "enough to get used to doing basic work with primitive or outmoded equipment and inadequately trained staff. Having overcome the shock of finding such conditions, they become of real use, but only if they stay at least one tour-and I feel a year is too short.

(3) Technicians, technicians, and more technicians! Let us have fewer highpowered specialists and more good, sound technicians who can turn out a reliable blood sugar, a good electrocardiogram, a bacteriological report worth the paper it is printed on-and be able to teach Africans to do the same.

(4) Overseas training programmes tha slant young African students towards the job or type of job the country needs when they come back. No more returning African with an M.Sc. degree whose graduate thesis concerns "the heat emission of glow-worm under simulated Arctic conditions," or " the digestive enzymes of the common parasites of the American potato beetle." Africa needs people who fit into the existing conditions and fill primary needs in the country's economy.

(5) Less talk and more action.

-I am, etc.,

\section{Medical Research Laboratory, \\ P.O. Box 30141, \\ Nairobi, Kenya.}

S. McClatchie.

\section{Health Centres}

SIR,-As one who believes implicitly that the health centre plan is neither feasible nor desirable and who has opposed the idea relentlessly over the years I am concerned that your series on such institutions may prove misleading.

There must be clear differentiation at the outset between the essential content of a health centre and the various forms in which it has been dressed up with additions from the normal local authority services. By and large the variations share with their original centre conception the feature of restricted access-i.e., the exclusion of outside doctors. When stripped of its appendages the health centre is found basically to consist of, first, surgery premises with appropriate staff, and, second, diagnostic facilities.

The first already existed at varying levels with all doctors; some with standards at least equa to "centre" concepts, some with abysmally low settings, and the vast majority ranging between these two. None received any form of subsidy, and it must be clear that the expense factor contained in capitation fees cannot be so described since it is received also by doctors working in the centres. In spite of this vital distinction surgeries have been the butt of illogical comparison with shiny new subsidized health centres. At long last there is promise of improvement in situ for medical practice in accordance with, it may be noted, a Liverpool resolution-passed by the B.M.A. at Belfast some three years ago (Supplement, 28 July 1962, p. 64)-calling for a separate expense factor related genuinely to expenses and not lists. This urgent need is met in the Charter-which itself has still to be met-and is included among the reasons why the profession must be resolute in its discussions and must not disarm during them.

The second constitutes the nucleus of a diagnostic centre and challenges the very building planned to contain it. In its situation it repudiates the cardinal principle that doctors of an area should be helped simultaneously-that is, battalions not single spies. Hospitals have conformed fully with this principle when opening their facilities directly to practitioners. It may be noted, however, that hospitals cannot be expected to cope with the future requests of resurgent medical practice and must welcome supplementation by diagnostic centres. Such centres can well include headquarters for a system of relief for doctors at nights, week-ends, sicknesses, or holidays, and can also accommodate clinical meetings, demonstrations, and other forms of enlightenment. Their purpose would be to serve doctors, not agglomerate patients, and subsidies would be well justified. All this alongside the surgery improvements envisaged above can uplift general practice and transform it into a rewarding life of zest, leisure, and postgraduate education. There is nothing Utopian about this, and practical proposals will shortly be considered in Liverpool.

Health centre propaganda has bedevilled planning long enough. Although cities are well supplied with surgeries and these distributed with greater convenience than ever conceivable with centres, it is actually preached that these surgeries should be uprooted wholesale and replaced by health centres. This folly is now so glaring that its advocates seek to invest group practices with health centre mystique. The Command Paper of April 1963 on Health and Welfare, however, makes the necessary admission, "The expectation that such centres would be widely provided overlooked the difficulties of shifting the main surgery of an established practice in a built-up area," and, "The circumstances which now justify their provision do not arise frequently." How responsible is a planner who "overlooked" the most obvious, long-established, and widespread condition in general practice?

The health centres in existence prove exactly nothing, although they include the effort in Stranraer, which is little short of a modified cottage hospital and is indeed admirably suited to its situation. They also include Manchester's Derbyshire House, where some $£ 60,000$ was spent on six doctors and nothing on twenty times that number of local colleagues, where expenses are reduced to a pittance, where lists of patients are limited, and where the balance of pay lost by this limitation is made up by the University. For seventeen years we have been subjected to glib comparisons between practitioners enjoying such conditions and those who have to pay "economic rents" as well as pay for every improvement to which they aspire. Liverpool's own example in Toxteth must be included. This building at present has six doctors who necessitate an annual subsidy of more than $£ 7,000$ quite apart from the initial capital outlay. Diagnostic facilities are not included. It is pertinent to speculate on the cost of an E.C.G. service for 20 times the centre's doctors and also to note that the Edinburgh diagnostic centre, serving every doctor in Edinburgh, has an annual running cost of only $£ 10,000$. It is further pertinent to wonder whether the planners, if they had included diagnostic facilities in Toxteth, would have dared to deny their use to outside doctors and, if not so denying, what reason survives for parking a few doctors inside? The answer relates to a slogan.

Whatever plans emerge it is even more vital that alongside them lists be slashedwithout financial detriment-and nonessential work trimmed mercilessly. The latter includes certification for industry as well as for National Insurance, and the former in no way implies a salaried service. There are enough doctors in the country for 